\title{
AST/ALT (De ritis) Ratio As a Prognostic Factor in Diffuse Large B-Cell Lymphoma
}

\author{
Serife Solmaz ${ }^{1 *}$, Ahmet Seyhanli ${ }^{2}$, Ozden Piskin², Mehmet Ali Ozcan², Inci Alacacioglu², Ahmet Alacacioglu ${ }^{3}$, \\ Fatih Demirkan², Bulent Undar ${ }^{2}$ and Guner Hayri Ozsan²
}

${ }^{1}$ Izmir Katip Celebi University Ataturk Training and Research Hospital, Hematology, IZMIR, Turkey

${ }^{2}$ Dokuz Eylul University Faculty of Medicine Hematology, IZMIR, Turkey

${ }^{3}$ Izmir Katip Celebi University Ataturk Training and Research Hospital, Oncology, IZMIR, Turkey

Submission: July 08, 2021; Published: July 19, 2021

*Corresponding author: Doc. Dr. Serife Solmaz, Izmir Katip Celebi Ataturk Training and Research Hospital, Hematology Department, Izmir, Turkey

Abstract

Purpose: This study aims to evaluate the prognostic significance of the aspartate aminotransferase (AST) / alanine aminotransferase (ALT) (De Ritis) ratio in diffuse large b-cell lymphoma ( DLBCL).

Material and Method: This retrospective study analyzed newly diagnosed DLBCL patients between December 2003- November 2016 in our hospital. We used the university archive to analyze patient information. De Ritis ratio were calculated using data from the blood samples at the time of diagnosis. We analyzed the effect of the De Ritis ratio on the overall survival (OS) of 225 patients with DLBCL.

Results: The mean age of the patients was $60.3(18-95)$ years, and $57.7 \%$ of them were males. We performed ROC curve analysis to calculate optimal cut off points for the De Ritis ratio at the time of diagnosed. The median De Ritis ratio was 1.30( range 0,26 - 5,84). Based on the cutoff points for the De Ritis ratio, patients were separated in two groups: high De Ritis ratio group ( $\geq 1.30$, n: 101 ) and low De Ritis ratio group ( $<1.30$, n:154) ( with sensitivity of 59\%, specifity of 40\%). We found a significant relationship between OS and De Ritis ratio. In Kaplan Meier analyses, the group with a higher De Ritis ratio had a more unfavorable prognosis for OS ( $\mathrm{p}=0.027$ ).

Conclusion: The De Ritis ratio may provide a cost- effective and sustainable marker for DLBCL patients. A higher De Ritis ratio can be considered as an independent prognostic factor in DLBCL patients.

Keywords: De Ritis Ratio; Overall survival; Diffuse Large B-Cell Lymphoma

\section{Introduction}

Diffuse large B cell lymphoma ( DLBCL) is a heterogeneous disease involving most of the cases of adult B cell lymphoma [1]. In Turkey, its incidence is $6 / 100,000$ on 2014 data [2]. There are many articles investigating prognostic markers useful in the prognosis of DLBCL in the literature. International Prognostic Index (IPI) consisting of age, serum lactate dehydrogenase (LDH), Eastern Cooperative Oncology Group (ECOG) performance status, Ann Arbor stage and involvement areas were used for risk classification of patients with DLBCL [3]. New prognostic scoring systems, such as the revised IPI (R-IPI) show a better capacity to predict the prognosis of patients with DLBCL than the conventional IPI [4]. However, the molecular and immunohistochemical tests were used in DLBCL for prognostic strategies recently, but these tests are sometimes costly and difficult to look at. Therefore, alternative prognostic biomarkers with lower costs are needed to determine risk in DLBCL patients. Fernando De Ritis found the ratio of alanine aminotransaminase (ALT) and aspartate aminotransaminase (AST) firstly and the ratio has been described since as the De Ritis ratio [5]. However, the some studies have showed that this ratio to be serious prognostic factors in different malignancies [6-8]. Bezan et al. [9] and Lee et al. [10] demonstrated that survival predicted outcomes in non-metastatic RCC patients and this rate was significantly associated with lower survival outcomes. We aimed to investigate the relationship between this ratio and survival outcomes of patients with DLBCL in our study.

\section{Subjects and Methods}

We analyzed newly diagnosed DLBCL patients between December 2003- November 2016 in our hospital. In this study, 


\section{Cancer Therapy \& Oncology International Journal}

we used the university archive to analyze patient information such as basic demographic features, duration of diagnosis, stage, treatment regimens, treatment results, and laboratory results. Blood samples of all patients were collected at the time of diagnosis or before the beginning of treatment. Plasma AST and ALT levels were analyzed by standard clinical methodology. De Ritis ratio were calculated using data from the blood samples at the time of diagnosis. We analyzed the effect of the De Ritis ratio on the overall survival (OS) of 225 patients with DLBCL.

\section{Ethics}

Informed consent was obtained from our patients at the time of diagnosis. Our study was designed as a retrospective evaluation of the files.

\section{Statistical Analysis}

All Statistical analysis were performed using Statistical Package for the Social Sciences (SPSS) statistics v 21.0 (Armonk, IBM Corp, N.Y., U.S.A). Pearson's Chi-square test for discrete variables or the Kruskal-Wallis test for continuous variables was used to compare the patient characteristics. The Kaplan-Meier method was used to estimate overall survival (OS). OS was defined as the time from diagnosis to death as a result of any cause. OS curves was compared using the log-rank test. We determined the optimum cutoff points for De Ritis ratio the as a predictor for OS based on the receiver operating characteristic (ROC) curve. The optimum cutoff points were the point on ROC curve. The effect of the De Ritis ratio on the overall survival (OS) was analyzed using the Kaplan-Meier method and multivariate Cox regression models. $\mathrm{P}<0.05$ was considered statistically significant.

\section{Results}

The clinicopathologic features of the patients are summarized in Table 1. Among 225 DLBCL patients, $57.8 \%$ were men, and $42.2 \%$ were women. The mean age of the patients was $60.3 \pm$ 16.4 (18-95) years. The patients were also categorized according to the Ann Arbor staging: $26(11.6 \%)$ patients as stage 1, 66 (29.3\%) as stage 2, $44(19.6 \%)$ as stage 3, and $89(39.6 \%)$ as stage 4 . We also calculated R-IPI scores of patients. R-IPI scores of patients found that were 36 patients $(16 \%)$ as score 0,127 patients (56\%) as score $1-2$ and 62 patients (28\%) as score 3-5. Extranodal involvement was observed in 109 patients ( $48.4 \%$ ). The distribution of extranodal sites is summarized in Table 1.

Table 1: The clinicopathologic features of the patients.

\begin{tabular}{|c|c|}
\hline Median age years ( range) & $60,3 \pm 16(18-95)$ \\
\hline $\begin{array}{c}\text { Sex } \\
\text { Male } \\
\text { Female }\end{array}$ & $\begin{array}{c}130 /(57,8 \%) \\
95 /(42,2 \%)\end{array}$ \\
\hline $\begin{array}{c}\text { Stage N / (\%) } \\
\text { Stage I } \\
\text { Stage II } \\
\text { Stage III } \\
\text { Stage IV }\end{array}$ & $\begin{array}{l}26 /(11,6 \%) \\
66 /(29,3 \%) \\
44 /(19,6 \%) \\
89 /(39,6 \%)\end{array}$ \\
\hline $\begin{array}{c}\text { R-IPI score N / (\%) } \\
\text { Score 0 } \\
\text { Score 1-2 } \\
\text { Score 3-5 }\end{array}$ & $\begin{array}{c}36 /(16 \%) \\
127 /(56 \%) \\
62 /(28 \%)\end{array}$ \\
\hline B symptoms N / (\%) & 77 / ( $34,2 \%)$ \\
\hline $\begin{array}{c}\text { The diagnostic sites } \mathrm{N}(\%) \\
\text { Lymph nodes } \\
\text { Oropharangeal and nasopharangeal masses } \\
\text { Gastrointestinal } \\
\text { Bone Marrow } \\
\text { Bone } \\
\text { Liver } \\
\text { Lung and mediastinal mass } \\
\text { Skin mass } \\
\text { Central nervous system } \\
\text { Female reproductive organs } \\
\text { Kidney } \\
\text { Thyroid gland } \\
\text { Testiculer } \\
\text { Spleen }\end{array}$ & $\begin{array}{c}100 /(44,4 \%) \\
33 /(14,6 \%) \\
33 /(14,6 \%) \\
16 /(7,1 \%) \\
9 /(4 \%) \\
8 /(3,6 \%) \\
5 /(2,3 \%) \\
5 /(2,3 \%) \\
4 /(1,8 \%) \\
3 /(1,3 \%) \\
3 /(1,3 \%) \\
3 /(1,3 \%) \\
2 /(0,9 \%) \\
1 /(0,5 \%)\end{array}$ \\
\hline $\begin{array}{c}\text { LDH } \\
\text { Normal } \\
\text { Above normal }\end{array}$ & $\begin{array}{l}124 /(55 \%) \\
101 /(45 \%)\end{array}$ \\
\hline
\end{tabular}

R-IPI; Revised International Prognostic Index, LDH; Lactate dehydrogenase 
Most of the patients (77.3\%, n:174 ) were treated with rituximab, cyclophosphamide, doxorubicin, vincristine, prednisolone (R -CHOP) at normal dosage, 26 patients (11.6\%) with reduced-dose R - CHOP, 6 patients (2.7\%) with Rituximab, cyclophosphamide, etoposide, vincristine, prednisolone $(\mathrm{R}$ CEOP), 8 patients (3.6\%) with Rituximab, cyclophosphamide, vincristine, prednisolone (R - CVP), 1 patient $(0.4 \%)$ with mini CEOP, 7 patients ( $3.1 \%$ ) with Rituksimab, steroid and 3 patients ( $1.3 \%$ ) with high dose methotrexate. However, high-risk patients received the proper intrathecal methotrexate as part of the CNS prophylaxis.
The complete remission ( CR ) of all patients was $88.4 \%$ $(n=199)$, the parsial remission ( PR) of all patients was $6.2 \%$ $(n=14)$ and the patient with refracter disease was $5.3 \%(n=12)$. Relapse disease was seen in 26 patients $(11.5 \%)$ of all patients. Median relapse time was 13.4 (range: 3-60 months) months. The median overall survival (OS) was 50 (range: 1-155 months ) months in all patients. The OS was 30 (range: 8-96 months ) months in relapse patients. The median follow-up period was 103 months (range: 93-113 months ) and during this period 77 deaths (34\%) were recorded. The median 3 year OS was $69 \%$, while 5 -year and 10 year OS was calculated as $65 \%$ and $60 \%$, respectively (Figure 1).

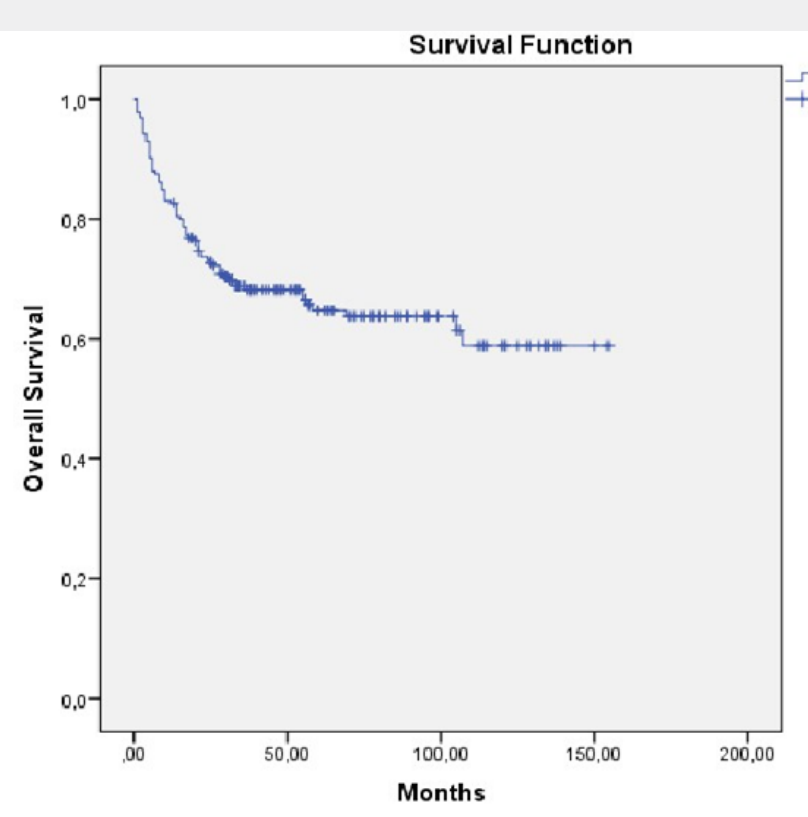

Figure 1. The overall survival of all patients.

The results show a significant statistical association between Ann-Arbor stage and OS [ $\mathrm{P}=0.002$, Figure 2 ]. The median OS was 133 (range: 112-153) months in patients with Ann-Arbor stage I; 113 (range: 96-130) months and 107 (range: 89-126) months in patients with Ann-Arbor stage II and Ann-Arbor stage III, respectivelly. Wheras in Ann-Arbor Stage IV patients it was found to be 75 (range: 62-88) months. The median 5 - year OS was $85 \%, 75 \%, 68 \%$ and $51 \%$ respectively accoring to the Ann-Arbor staging (Table 2).

A significant statistical difference was observed between R-IPI scores and OS ( $\mathrm{P}=0.0001$, Figure 3 ). The median OS was 139 (range: 124-154) months in patients with R-IPI score 0, 105 (range: 93-117) months in patients with R-IPI score of 1-2, and 64 (range: 48-79) months in patients with R-IPI score of 3-5. The median 5 - year OS was $89 \%, 68 \%$ and $46 \%$ according to the respective R-IPI (Table 2). Similarly, patients with above normal LDH (n: 101) had shorter survival time than the patients with normal LDH (n: 124) ( OS: 91 (range: 76-105) months vs 113 (range: 100-126) months, $\mathrm{P}=0.015$ ). We performed ROC curve analysis to calculate optimal cut off points for the De Ritis ratio at the time of diagnosed. The median De Ritis ratio was 1.30 ( range 0.26 - 5.84 ). Based on the cutoff points for the De Ritis ratio, patients were separated in two groups: high De Ritis ratio group ( 21.30, n: 71 ) and low De Ritis ratio group ( $<1.30, \mathrm{n}: 154$ ) ( with sensitivity of $59 \%$, specifity of $40 \%$ ). The group with high De Ritis ratio had shorter OS than the group with low De Ritis ratio ( OS: 46 (64-82) months vs 73 (38-54) months). The median 5-year OS was $70 \%$ in patients with low De Ritis ratio at 5-year, however it was $52 \%$ in patients with high De Ritis ratio.

A significant statistical relationship was found between OS and De Ritis ratio. In KaplanMeier analysis, the group with a higher De Ritis ratio had a more unfavorable prognosis ( $p=0.027$ ) (Figure 4). Hepatic dysfunction was detected in $7.2 \%$ of patients (n:16). We found that the De Ritis ratio was effected on survival 


\section{Cancer Therapy \& Oncology International Journal}

outcomes independent of liver involvement ( $p=0.86$ ). the HBV infection infection status of all patient are as shown in Table 2. Sixteen patients out of 27 patients with chronic viral hepatitis

have low De ritis ratio. There were no- significant association between high De Ritis ratio and chronic viral hepatitis on survival outcomes $(\mathrm{P}=0.54)$.

Table 2: The overall survival according to Ann-Arbor stage, R-IPI scores and De Ritis ratio.

\begin{tabular}{|c|c|c|c|}
\hline & Events/N & Months/5-y estimate & $P$ value \\
\hline $\begin{array}{l}\text { De Ritis ratio } \\
\text { Low De Ritis ratio } \\
\text { High De Ritis ratio }\end{array}$ & $\begin{array}{c}154 /(68,4 \%) \\
71 /(31,6 \%)\end{array}$ & $\begin{array}{l}46 / 70 \% \\
73 / 52 \%\end{array}$ & $P=0,0270$ \\
\hline $\begin{array}{c}\text { Ann-Arbor stage } \\
\text { Stage I } \\
\text { Stage II } \\
\text { Stage III } \\
\text { Stage IV }\end{array}$ & $\begin{array}{l}26 /(11,6 \%) \\
66 /(29,3 \%) \\
44 /(19,6 \%) \\
89 /(39,6 \%)\end{array}$ & $\begin{array}{c}133 / 85 \% \\
113 / 75 \% \\
107 / 68 \% \\
75 / 51 \%\end{array}$ & $P=0,0020$ \\
\hline $\begin{array}{c}\text { R-IPI scores } \\
\text { R-IPI score } 0 \\
\text { R-IPI score 1-2 } \\
\text { R-IPI score 3-5 }\end{array}$ & $\begin{array}{c}36 /(16 \%) \\
127 /(56 \%) \\
62 /(28 \%)\end{array}$ & $\begin{array}{c}139 / 89 \% \\
105 / 68 \% \\
64 / 46 \%\end{array}$ & $P=0,0001$ \\
\hline
\end{tabular}

R-IPI; Revised International Prognostic Index

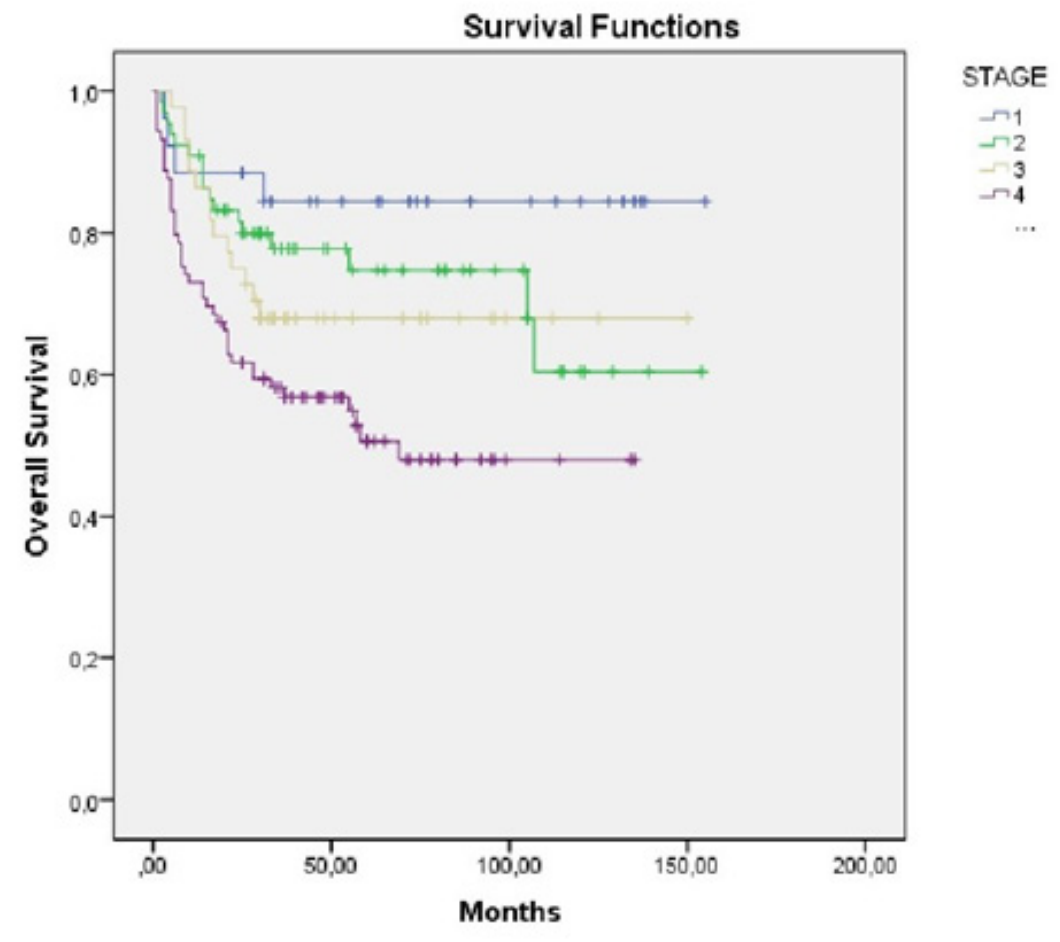

Figure 2. Survival curves according to Ann - Arbor stage. 


\section{Cancer Therapy \& Oncology International Journal}

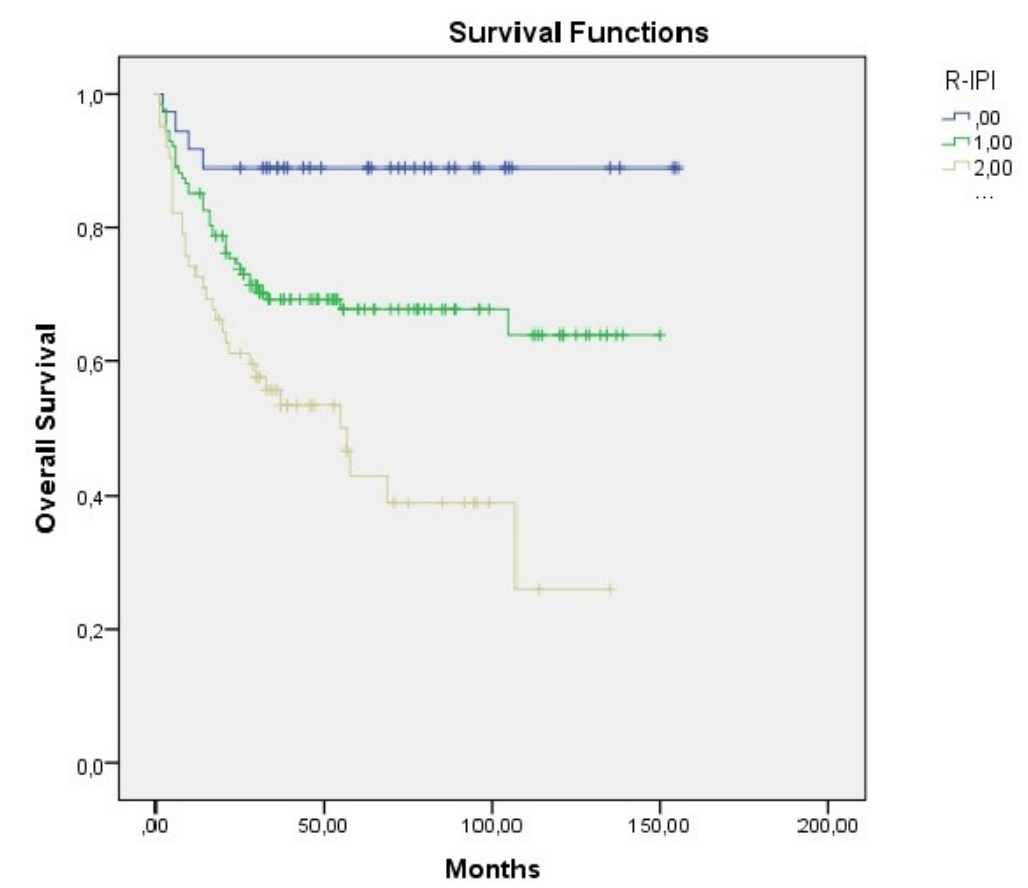

Figure 3. Survival curves according to R-IPI scores.

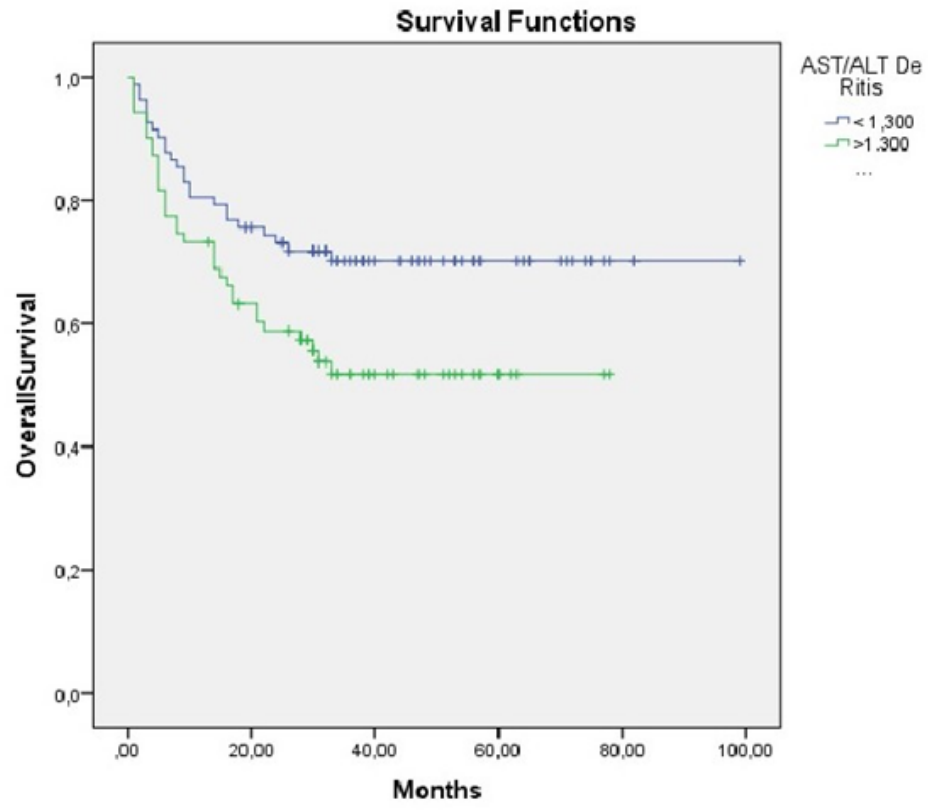

Figure 4. The impact of De Ritis ratio on overall survival in diffuse large b cell lymphoma patients. 
Based on the Cox regression models adjusted for clinical parameters for $\mathrm{OS}$, the De Ritis ratio ( $\mathrm{P}=0.003)$, age $(\mathrm{P}=0$ $.008)$ andAnn-Arbor stage $(p=0.05)$ were found as independent prognostic factors.

\section{Discussion}

There are many articles investigating prognostic markers useful in the prognosis of DLBCL in the literature. The effect of De Ritis ratio on cancer prognosis has been invastigated in many studies. These different results guide our patient follow-up. The serum AST and ALT levels are related to the extend of liver damage. The AST and ALT levels may be elevated due to hypoxia, trauma, ischemia ordamage of cell membrane. The association between AST and cancer is uncertain, however malign cells can produce AST. Thus, it is known that AST plays an important in carcinogenesis $[11,12]$. The high AST/ALT ratio may be also related to elevated oxidative stress and inflamatory environment. Various studies have already reported that inflamation and oxidative stress play an important role in carcinogenesis [11-16].

Numerous studies have reported the application of aminotransaminase as a prognostic indicator in various cancers $[17,18]$. Kiba et al. [19] reported a bad prognosis in patients with multiple myeloma with a high AST level. Hepatic dysfunction was observed in 7 patients $(15,9 \%)$ in this study, these patients were serologically negative for hepatitis B and C. Also, abdominal ultrasonography or computerized tomography demonstrated that it was related to liver involvement with MM (2 cases, 4,5\%). The study of Lu et al, reported association between the serum AST level and prognosis in DLBCL patients [20]. They showed that a high pretreatment AST level association a negative prognostic factor for in DLBCL patients. The De Ritis ratio, was first reported in 1957 as a useful indicator for hepatitis [5]. Recently, the De Ritis ratio is concidered a good predictor of liver function damage, and is widely used to evaluate various causes of liver disease. Furthermore, the De Ritis ratio is associated with non-hepatic diseases, as diabetes mellitus, peripheral arterial occlusive disease, acute ischemic stroke [21-23].

Than, the effect of De Ritis ratio on cancer prognosis has been reported in many studies. A high De Ritis ratio was related to poor survival outcomes in patients with RCC [8-10,24-26], liver cancer [27-30], urinary tract urotheliel carcinoma [7,31,32]. Ha et al. showed a significant relationship of elevated AST/ALT ratio and poor OS in bladder cancer that underwent surgery [33]. The other study was found that a higher preoperative AST/ ALT ratio predicts poor outcome in patients with bladder cancer [34]. The other studies have shown also similar results in patients with head and neck and prostat cancers [6,35].

The meta-analysis of $\mathrm{Wu}$ at al. showed that the pre-treatment high level of serum AST/ALT ratio is significantly associated with poor clinical outcomes of OS, cancer-specific survival, and recurrence-free survival in patients with solid tumors ( $\mathrm{p}<0.001)$.
They said that the pretreatment De Ritis ratio may serve as a useful prognostic predictor for malignant patients [36]. This ratio has been shown to be the predictor of survival in malignancies in the literature, but this has not show in hematological diseases. In our study we investigated the relationship between the De Ritis ratio and survival outcomes of patients with DLBCL. We found that the patients with the high De Ritis ratio had an unfavorable prognosis for OS. In our study, we showed that De Ritis ratio can be a prognostic marker for predicting survival with respect to the Ann Arbor stage and R-IPI score. Low De ritis ratios are typical for chronic viral hepatitis, however high De rirtis ratio can be found in chronic hepatitis when progression to fibrosis and cirrhosis $[37,38]$. In our study, reports similar findings with sixteen of 27 patients with chronic viral hepatitis have low De ritis ratio. However, the number of patients is quite low. We showed that De Ritis Ratio was low-cost and easy-to-acces test that predicted OS in DLBCL patients. However, the results of this issue are still controversial in the literature and there is no consensus. Furthermore, this study is limited as it was population, and prospective studies with more patients may berequired.

\section{Conclusion}

In conclusion, the De Ritis ratio may provide a cost- effective and sustainable marker for DLBCL patients. A higher De Ritis ratio can be considered as an independent prognostic factor in DLBCL patients who treated with lymphoma therapy (R-CHOP, R-CVP). However, this results need to be confirmed and corroborated by comprehensive prospective randomized studies with an appropriate design.

\section{Acknowledgment}

Professional medical writing support and editor assistance were not supported by the company.

\section{Financial support and sponsorship}

None.

\section{Conflict of Interest}

The authors declare no conflict of interests. All the authors contributed equally to this article.

\section{References}

1. Nowakowski GS, Feldman T, Rimsza LM, Westin JR, Witzig TE, et al. (2019) Integrating precision medicine through evaluation of cell of origin in treatment planning for diffuse large B-cell lymphoma. Blood Cancer J 48: 1-10.

2. Republic of Turkey (2014) Ministry of Health 2014 Statistics. Basaran BB, Guler C, Yentur GK (eds), Ankara, Ministry of Health, Republic of Turkey.

3. Shipp MA, Harrington DP, Anderson JR, Amitage JH, Bonadonna G, et al. (1993) A predictive model for aggressive non-Hodgkin's lymphoma. The International Non-Hodgkin's Lymphoma Prognostic Factors Project. N Engl J Med 329(14): 987-994. 


\section{Cancer Therapy \& Oncology International Journal}

4. Sehn LH, Berry B, Chhanabhai M, Fitzgerald C, Gill K, et al. (2007) The revised International Prognostic Index (R-IPI) is a better predictor of outcome than the standard IPIfor patients with diffuse large B-cell lymphoma treated with R-CHOP. Blood 109(5): 1857-1861.

5. De Ritis F, Coltorti M, Giusti G (1957) An enzymic test for the diagnosis of viral hepatitis; the transaminase serum activities. Clin Chim Acta 2(1): 70-74.

6. Takenaka Y, Takemoto N, Yasui T, Yamamoto Y, Uno A, et al. (2016) Transaminase Activity Predicts Survival in Patients with Head and Neck Cancer. PLoS One 11(10): e0164057.

7. Lee H, Choi YH, Sung HH, Han DH, Jeon HG, et al. (2017) De Ritis Ratio (AST/ALT) as a Significant Prognostic Factor in Patients With Upper Tract Urothelial Cancer Treated With Surgery. Clin Genitourin Cancer 15(3): 379-385.

8. Canat L, Ataly HA, Agalarov S, Alkan I, Altunrende F (2018) The effect of AST/ALT (De Ritis) ratio on survival and its relation to tumor histopathological variables in patients with localized renal cel carcinoma.Int Braz J Urol 44(2): 288-295.

9. Bezan A, Mrsic E, Krieger D, Stojakovic T, Pummer K, et al. (2015) The Preoperative AST/ALT (De Ritis) Ratio Represents a Poor Prognostic Factor in a Cohort of Patients with Nonmetastatic Renal Cell Carcinoma. J Urol 194(1): 30- 35.

10. Lee H, Lee SE, Byun SS, Kim HH, Kwak C, et al. (2017) De Ritis ratio (aspartate transaminase/alanine transaminase ratio) as a significan prognostic factor after surgical treatment in patients with clear-cell localized renal cell carcinoma: a propensity score-matched study. BJU Int 119(2): 261-267.

11. Birtle A, Lawton P, Chaundary M, Richman P, McFarlane B (2003) Unexplained high AST in locally advanced breast cancer. Breast J 9(6): 505-506.

12. Chen SL, Xue N, Wu MT, Chen H, He X, et al. (2016) Influence of preoperative serum aspartate aminotransferase (AST) level on the prognosis of patients with non-small cell lung Cancer. Int J Mol Sci 17(9): 1-12.

13. Chen SL, Li JP, Li LF, Zeng T, He X (2016) Elevated preoperative serum alanine aminotransferase/aspartate aminotransferase (ALT/AST) ratio is associated with better prognosis in patients undergoing curative treatment for gastric adenocarcinoma. Int J Mol Sci 17(6): $1-11$.

14. Ruart M, Chavarria L, Campreciós G, Suárez-Herrera N, Montironi C, et al. (2019) Impaired endothelial autophagy promotes liver fibrosis by aggravating the oxidative stress response during acute liver injury. J Hepatol 70(3): 458-469.

15. Cairns RA, Harris IS, Mak TW (2011) Regulation of cancer cell metabolism. Nat Rev Cancer 11(2): 85-95.

16. Elf SE, Chen J (2014) Targeting glucose metabolism in patients with cancer. Cancer 120(6): 774-780.

17. Ou Y, Huang J, Yang L (2018) The prognostic significance of pretreatment serum $\gamma$-glutamyltranspeptidase in primary liver cancer: a metaanalysis and systematic review. Biosci Rep 38(6): 1-13.

18. Metwalli AR, Rosner IL, Cullen J, Chen Y, Brand T, et al. (2014) Elevated alkaline phosphatase velocity strongly predicts overall survival and the risk of bone metastases in castrate-resistant prostate cancer. Urol Oncol 32(6): 761-768.

19. Kiba T, Ito T, Nakashima T, Okikawa Y, Kido M, et al. (2014) Bortezomib and dexamethasone for multiple myeloma: higher AST and LDH levels associated with a worse prognosis on overall survival. BMC Cancer 14 462-471.

20. Lu TX, Wu S, Cai DY, Hong TT, Zhang Y, et al. (2019) Prognostic significance of serum aspartic transaminase in diffuse large B-cell lymphoma. BMC Cancer 19(1): 553

21.Zoppini G, Cacciatori V, Negri C, Stoico V, Lippi G, et al. (2016) The aspartate aminotransferase-to-alanine aminotransferase ratio predicts all-cause and cardiovascular mortality in patients with type 2 diabetes. Medicine (Baltimore) 95(43): e4821.

22. Rief P, Pichler M, Raggam R, Hafner F, Gerger A, et al. (2016) The AST/ALT (De-Ritis) ratio: a novel marker for critical limb ischemia in peripheral arterial occlusive disease patients. Medicine (Baltimore) 95(24): e3843.

23. Gao F, Chen C, Lu J, Zheng J, Ma XC, et al. (2017) De Ritis ratio (AST/ ALT) as an independent predictor of poor outcome in patients with acute ischemic stroke. Neuropsychiatr Dis Treat 13: 1551-1557.

24. Kang M, Yu J, Sung HH, Jeon HG, Jeong BC, et al. (2018) Prognostic impact of the pretreatment aspartate transaminase/alanine transaminase ratio in patients treated with first-line systemic tyrosine kinase inhibitor therapy for metastatic renal cell carcinoma. Int J Urol 25(6): 596-603

25. Ishihara H, Kondo T, Yoshida K, Omae K, et al. (2017) Evaluation of preoperative aspartate transaminase/alanine transaminase ratio as an independent predictive biomarker in patients with metastatic renal cell carcinoma. Clin Genitourin Cancer 15(5): 598-604

26. Gu L,Wang Z, Chen L, Ma X, Li H, et al. (2017) A proposal of postoperative nomogram for overall survival in patients with renal cell carcinoma and venous tumor thrombus. J Surg Oncol 115(7): 905-912.

27. Liu C, Jia BS, Zou BW, Du H, Yan LN, et al. (2017) Neutrophil-tolymphocyte and aspartate-to-alanine aminotransferase ratios predict hepatocellular carcinoma prognosis after transarterial embolization. Medicine (Baltimore) 96(45): 8512.

28. Chen J, Huang C, Chen K, Li S, Zhang X, et al. (2018) Overexpression of $\mathrm{LBH}$ is associated with poor prognosis in human hepatocellular carcinoma. Onco Targets Ther 11: 441-448.

29. Xie X, Yao M, Chen X, Lu W, Lv Q, et al. Reduced red blood cell count predicts poor survival after surgery in patients with primary liver cancer. Medicine(Baltimore) 94(8): e577.

30. Kao WY, Chiou YY, Hung HH, Chou YH, Su CW, et al. (2011) Risk factors for long-term prognosis in hepatocellular carcinoma after radiofrequency ablation therapy the clinical implication of aspartate aminotransferase-platelet ratio index. Eur J Gastroenterol Hepatol 23(6): 528-536.

31. Nishikawa M, Miyake H, Fujisawa M (2016) De Ritis (aspartate transaminase/ alanine transaminase) ratio as a significant predictor of recurrence-free survival in patients with upper urinary tract urothelial carcinoma. Urol Oncol 34(9): e9- 417.

32. Cho YH, Hwang JE, Chung HS, Kim MS, Hwang EC, et al. (2017) The De Ritis (aspartate transaminase/alanine transaminase) ratio as a predictor of oncological outcomes in patients after surgery for upper urinary tract urothelial. Int Urol Nephrol 49(8): 1383-1390.

33. Ha YS, Kim SW, Chun SY, Chung JW, Choi SH, et al. (2019) Association between De Ritis ratio (aspartate aminotransferase/alanine aminotransferase) and oncological outcomes in bladder cancer patients after radical cystectomy. BMC Urol 19(1): 10-18.

34. Gorgel SN, Kose O, Koc EM, Ates E, Akin Y, et al. (2017) The prognostic significance of preoperatively assessed AST/ALT (De Ritis) ratio on survival in patients underwent radical cystectomy. Int Urol Nephrol 49(9): 1577-1583.

35. Miyake H, Matsushita Y, Watanabe H, Tamura K, Suzuki T, et al. (2018) Significance of De Ritis (aspartate transaminase/alanine transaminase) ratio as a significant prognostic but not predictive biomarker in Japanese patients with metastatic castration- resistant prostate cancer treated with cabazitaxel. Anticancer Res 38(7): 4179-4185. 


\section{Cancer Therapy \& Oncology International Journal}

36. Wu J, Chen L, Wang Y, Tan W, Huang Z (2019) Prognostic value ofaspartate transaminase to alanine transaminase (De Ritis) ratio in solid tumors: a pooled analysis of 9,400 patients. Onco Targets Ther 12: 5201-5213.

37. Williams AL, Hoofnagle JH (1988) Ratio of serum aspartate to alanine aminotransferase in chronic hepatitis; relationship to cirrhosis Gastroenterology 95: 734-739.
38. Fortunato G, Castaldo G, Oriani G, Cerini R, Intrieri M, et al. (2001) Multivariate discriminant function based on six biochemical markers in blood can predict the cirrhotic evolution of chronic hepatitis. Clin Chem 47(9): 1696-700.
This work is licensed under Creative Commons Attribution 4.0 License DOI:10.19080/CTOIJ.2021.19.556010
Your next submission with Juniper Publishers will reach you the below assets

- Quality Editorial service

- Swift Peer Review

- Reprints availability

- E-prints Service

- Manuscript Podcast for convenient understanding

- Global attainment for your research

- Manuscript accessibility in different formats

( Pdf, E-pub, Full Text, Audio)

- Unceasing customer service

Track the below URL for one-step submission https://juniperpublishers.com/online-submission.php 